\title{
A Wideband Reflector-Backed Antenna for Applications in GPR
}

\author{
A. Raza $\mathbb{D}^{1},{ }^{1}$ W. Lin $\mathbb{D}^{2},{ }^{2}$ M. K. Ishfaq $\mathbb{D}^{1},{ }^{1}$ M. Inam $\mathbb{D}^{3},{ }^{3}$ F. Masud ${ }^{(D)},{ }^{4}$ and M. H. Dahri $\mathbb{D}^{5}$ \\ ${ }^{1}$ Department of Electrical Engineering, Government College University Faisalabad, Faisalabad, Pakistan \\ ${ }^{2}$ School of Mathematics and Physics, University of South China, Hengyang 421001, China \\ ${ }^{3}$ Faculty of Electrical and Electronic Engineering Technology, Universiti Teknikal Malaysia Melaka (UTeM), \\ Melaka 76100, Malaysia \\ ${ }^{4}$ Department of Statistics and Computer Science, University of Veterinary \& Animal Sciences, Lahore, Pakistan \\ ${ }^{5}$ Dawood University of Engineering and Technology, Karachi, Pakistan
}

Correspondence should be addressed to M. Inam; muhammad_inamabbasi@yahoo.com

Received 10 September 2021; Revised 20 October 2021; Accepted 26 October 2021; Published 8 November 2021

Academic Editor: Mohammad Alibakhshikenari

Copyright $(92021$ A. Raza et al. This is an open access article distributed under the Creative Commons Attribution License, which permits unrestricted use, distribution, and reproduction in any medium, provided the original work is properly cited.

\begin{abstract}
A resistively loaded wideband slotted patch antenna with optimized performance on lower frequencies is proposed for groundpenetrating radar (GPR) applications. The proposed design is backed by an optimized reflector composed of a periodic array of square loop elements, which enhances the antenna's gain and directivity. The antenna shows good radiation characteristics and ease of integration with the GPR systems. The proposed structure features a compact size and wide bandwidth covering from 0.6 to 4.6 GHz. The peak gain of $7 \mathrm{dBi}$ is achieved. The fabricated prototype of the antenna along with an integrated optimized reflective surface has overall dimensions of $18 \times 22 \times 5 \mathrm{~cm}^{3}$. The measured results validate the antenna's performance in both free space and sandy medium, which enlighten its use for GPR applications.
\end{abstract}

\section{Introduction}

Ground-penetrating radar (GPR) is an important technology developed for short-range radar applications. Electromagnetic waves are used for the detection of metallic and nonmetallic buried objects. Nowadays, GPR use not only is limited to subsurface and through wall utility detection but also has a wide range of applications in the commercial sector including nondestructive testing, explorations in mining, disaster relief work, and discovery of hidden tunnels. GPR has gained popularity due to its effectiveness in the civil and geological structural investigation. Unlike conventional radar, GPR signals travel in the lossy and inhomogeneous mediums varying in properties. With investigation of buried static targets at different depths, antennas employed in GPR should have ultrawideband characteristics. High frequencies are used for the detection of small targets in shallow depths; whereas low frequencies are used for the detection of large and deeper targets. Therefore, antennas used in GPR have an operating frequency ranging from a few $\mathrm{MHz}$ to $\mathrm{GHz}$ covering a decade bandwidth [1].

Two common types of GPR systems are impulse GPR and continuous wave GPR. Most commercially available GPR systems incorporate impulse techniques. In these systems, a time-domain pulse is transmitted by the antenna and a reflected wave is received; short-duration pulse of nanosecond duration is used to achieve a broad bandwidth. Therefore, the antenna performs as an essential part of impulse GPR system performance, whereas continuouswave GPR systems operate in the frequency domain and transmit continuously. A significant challenge in a continuous wave, both swept frequency and stepped frequency technique, is the synchronization of time in the entire sweep $[2,3]$.

For optimization of GPR antenna, several aspects including physical dimension, weight, impedance bandwidth, and footprint are considered. In recent years, many GPR antennas are designed for a diverse range of applications including civilian and military, as well as security services. A 
transverse electromagnetic (TEM) horn antenna for aircoupled impulse GPR applications is presented in [4]; it operates in the broad frequency range between 0.6 and $6 \mathrm{GHz}$. A dipole antenna, in [5], is presented for structural investigation, operating in the frequency range from 0.45 to 1.1 GHz. Although 3D antennas such as horn [4], dipole [5], cone [6], and spiral [7] provide satisfactory GPR performances, their $3 \mathrm{D}$ structure led to an increase in size and weight of the antenna.

To address this issue, various planner antennas were proposed. The tapered slot antennas can be a good competitor because of their end-fire radiation, moderate gain, small dimensions, low-cost components, and easy fabrication. A few slotted designs were also presented like a CPWfed tapered slot antenna [8], operating in 0.64 to $6 \mathrm{GHz}$, and a compact slot antenna [9], operating in 1.4 to $3.5 \mathrm{GHz}$. These slot-loaded designs are fed by the coplanar waveguide and are compact but have the disadvantage of low gain and low resolution, as back radiation of the antenna is of no use in the GPR system. Therefore, absorbing materials are used to avoid interference with the communication spectrum [10]. This back radiation can be used to illuminate the ground. Thus, some solutions are suggested for constructively enhancing the gain of planner antennas [11-16]. In the antenna casing of GPR, the use of a reflector, cavity, electromagnetic band-gap (EBG) structure, loop directors, and choke rings [17-21] is proposed for high gain GPR applications.

In this study, a compact and wideband reflector backed slotted patch antenna, suitable for applications in GPR, is presented. The proposed design provides a wide bandwidth from $0.6 \mathrm{GHz}$ to $4.6 \mathrm{GHz}$. Furthermore, a reflective surface is designed to enhance the radiation performance of the antenna, especially at lower frequencies. The proposed antenna is compact and is constructed using low cost and lightweight materials, as well as its simple structure provides ease in fabrication. The presented antenna is tested under soil conditions to ensure its application for GPR. Also, the proposed design can be used simultaneously for $2 \mathrm{G}, 3 \mathrm{G}, 4 \mathrm{G}$, and 5G applications as it covers 900/1800/1900/2100/2600/ $3500 \mathrm{MHz}$ frequency bands.

\section{Antenna Description}

The geometrical structure of the planner slotted patch antenna (SPA) is shown in Figure 1. The antenna is fabricated using low cost and lightweight materials. The radiating structure is printed over a $1.6 \mathrm{~mm}$ thick FR-4 substrate with relative permittivity of 4.4 . To have better control over characteristics impedance, the SPA antenna is fed by a tapered feed. The patch antenna has numerous advantages, such as being lightweight, low cost, and high gain, as compared to the CPW counterpart [22].

Therefore, the antenna-radiating structure is optimized to minimize aperture reflections and achieve wideband operation while keeping the antenna size small. Generally speaking, the mentioned antenna is geometrically designed using four elliptical patches. The big elliptical patches, having radii ER1 and ER2, are parallel to each other and orthogonal to two small patches of radii ER3 and ER4. This configuration created a uniformly tapered bowtie-shaped radiating slot with a separation of $2 \mathrm{~mm}$ in the middle and $20 \mathrm{~mm}$ on the sides. The uniformly tapered bowtie-shaped radiating slot changes the direction and effective length of surface current on the radiator $[23,24]$. A resistor is placed at the center of the slot for lower band operation. This design is termed as a resistive loaded slotted patch antenna (RLSPA). The planner antenna covers a dimension of $18 \times 22 \mathrm{~cm}^{2}$. The antenna is further fine tuned using an inbuilt optimizer of antenna simulation software. The detailed dimensions of the antenna are described as below (in millimeters): $L=220, W=180, \mathrm{ER} 1=80, \mathrm{ER} 2=25, \mathrm{ER} 3=35$, $\mathrm{ER} 4=12, \mathrm{LF}=111, \mathrm{WF}=3.6, L 1=3.8, L 2=19.5, g=0.6$, $\mathrm{Lg}=110, L 3=20.6, L 4=20.2, \mathrm{SH}=60$, and $D=50$. The geometrical structure of the proposed reflector-backed antenna along with the fabrication is shown in Figure 2. The reflector comprises a $4 \times 4$ slot array, where the size of each slot is $2 \times 3 \mathrm{~cm}^{2}$.

\section{Working Principle}

A typical antenna in an impulse radar system should operate in a lower range of frequencies with compact dimensions. Therefore, the equivalent circuit of the reflector-backed antenna is investigated, as shown in Figure 3. The structure can be divided into three parts: (1) a square inductive metallic ring, (2) capacitive slot, and (3) ground plane of RLSPA act as a metallic layer [25].

The ground plane is modelled as inductance Lh and the layer between reflector and ground plane has capacitance coupling, which is represented as Ch [24, 25]. By using transmission line theory, the equivalent circuit input impedance can be expressed as a combination of inductive and capacitive components of the reflective surface as

$$
\begin{aligned}
Z_{L} & =\frac{1}{j \omega C_{h}}, \\
Z_{H} & =\frac{1}{\left(1 / j \omega L_{1}\right)+\left(1 / j \omega L_{h}\right)} .
\end{aligned}
$$

The antenna's performance can be determined by many parameters including antenna size, radiation characteristics, bandwidth, and stable gain. Aperture reflections are a considerable cause of the reduction in radiation efficiency of UWB antennas for GPR [17].

GPR antennas have to satisfy a broad frequency band for better imaging resolution of the GPR system. Consequently, the removal of discontinuous points in radiation structure is considered an important optimization factor while designing. Also, slot loading, resistive loading, tapered feed, and curved ground have been utilized, and their effect to achieve specific antenna performance for GPR is recorded, respectively, and the results are described.

3.1. Effect of the Loaded Resistor. The resistive loading is used in many GPR antenna designs $[7,8]$, which is an effective method for bandwidth enhancement on lower frequencies 


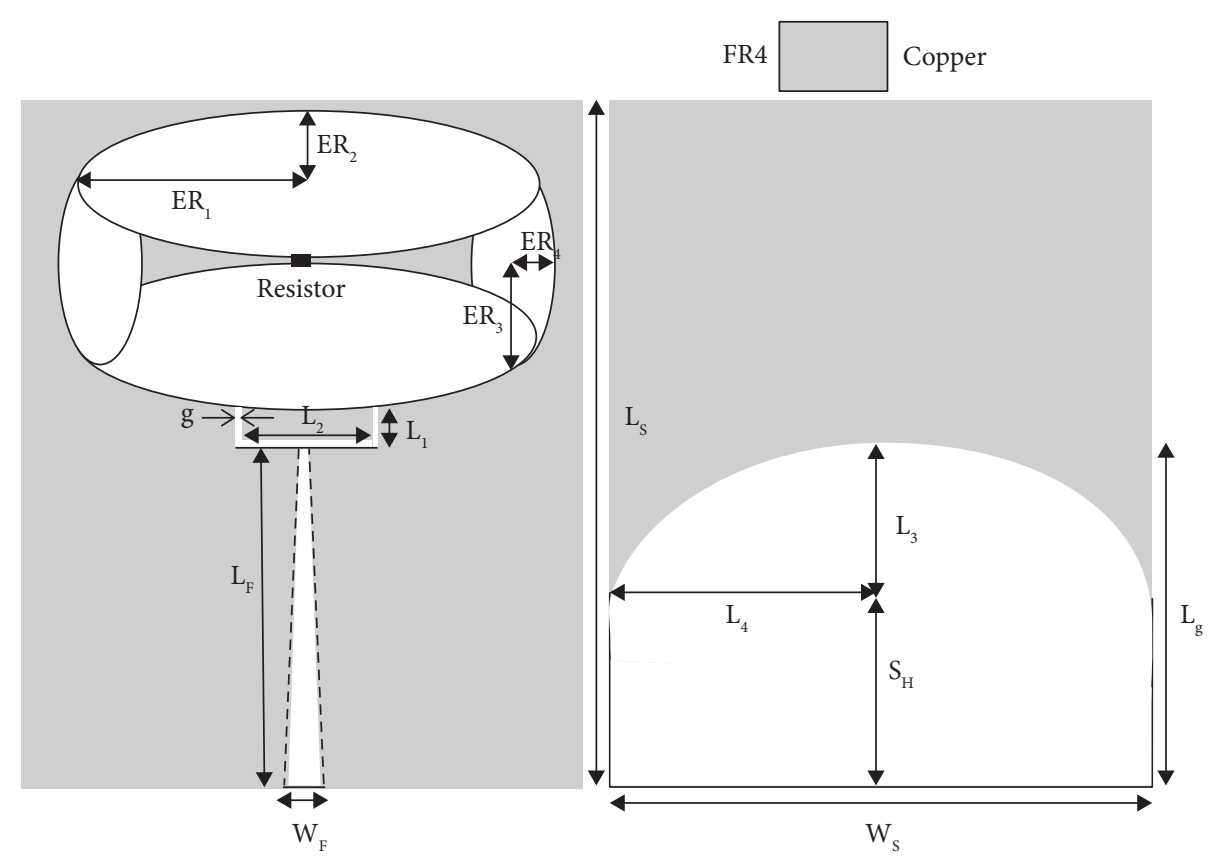

FIGURE 1: Geometrical construction of the planner SPA: (a) top radiator and (b) bottom view (ground plane).

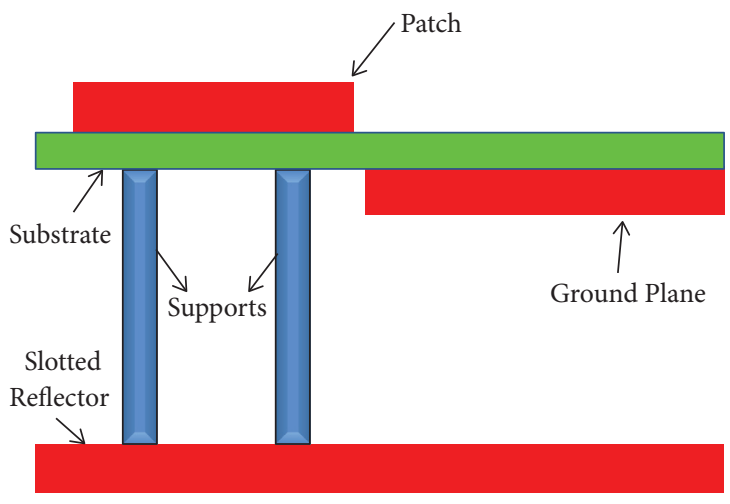

(a)

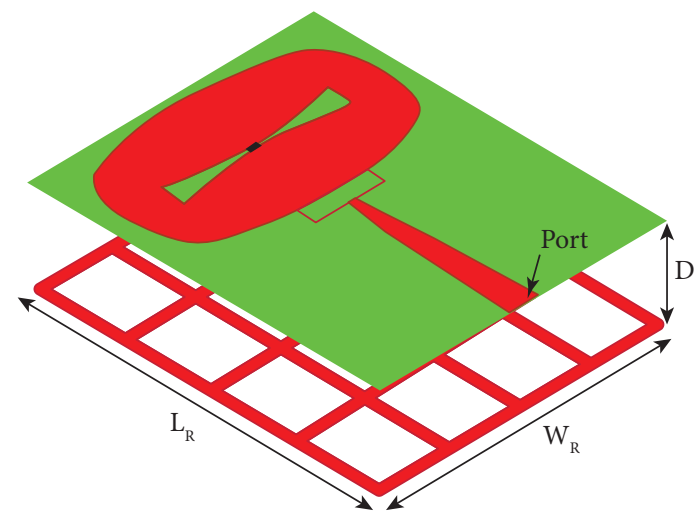

(b)

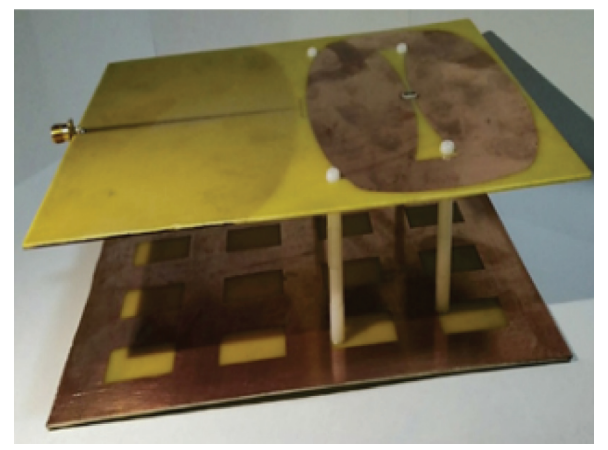

(c)

FIGURE 2: Geometry of the reflector-backed antenna: (a) side view (b) 3D view; (b) reflector-backed fabricated antenna.

while keeping the size of the antenna small. The optimal resistance value of $50 \Omega$ is used for better impedance matching. Figure 4 shows the voltage standing wave ratio (VSWR) of SPA and resistively loaded slotted patch antenna
(RLSPA). After the optimization process, the surface current distribution at frequency $1 \mathrm{GHz}$ of the SPA and RLSPA is shown in Figure 5. However, the use of resistors may introduce extra losses in the antenna. The antenna structure is 


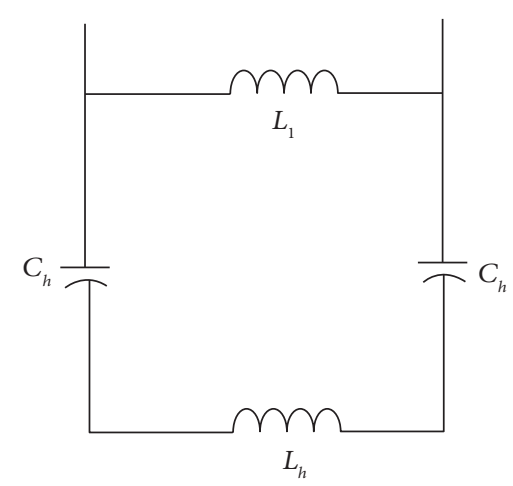

FIGURE 3: Equivalent circuit of the proposed reflector-backed antenna.

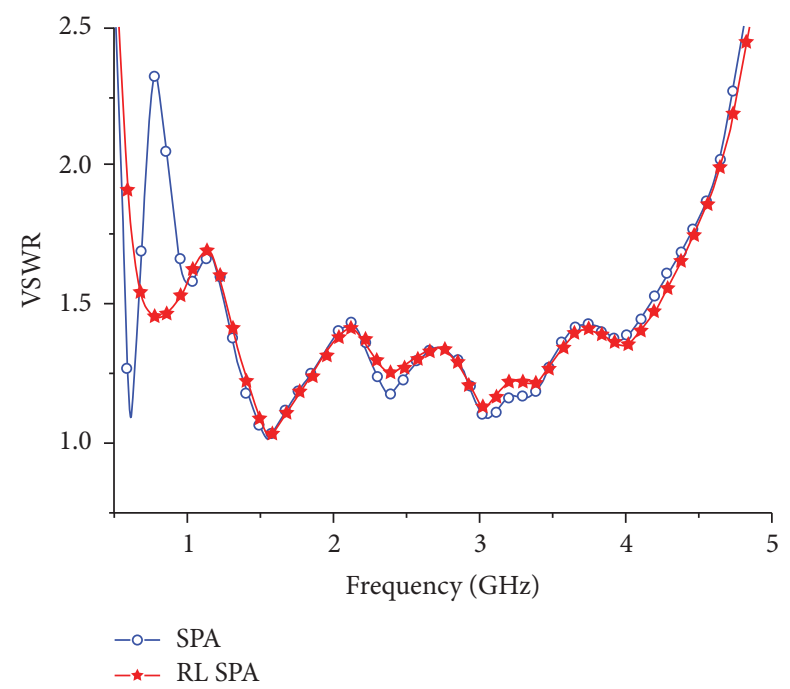

Figure 4: The VSWR of SPA and RLSPA.

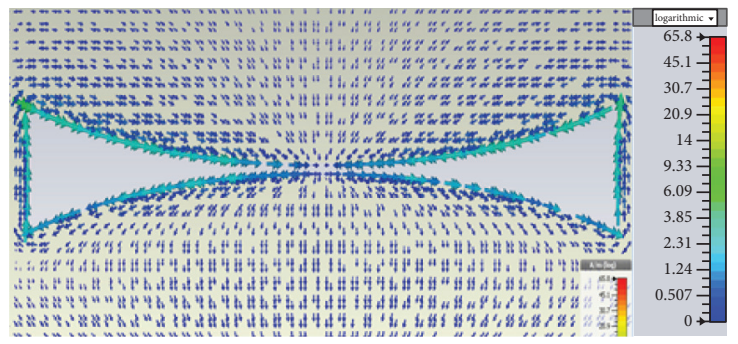

(a)

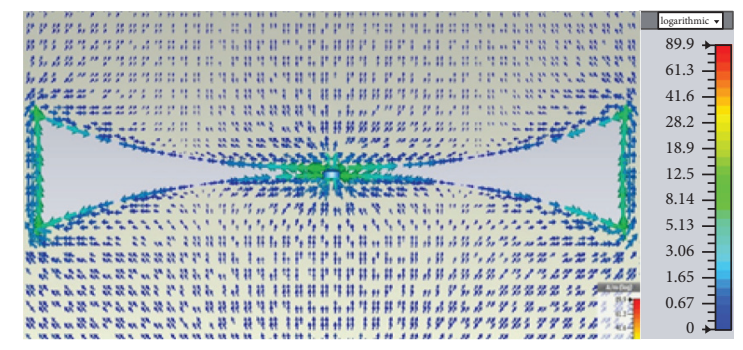

(b)

FIgURE 5: Construction of the antenna: (a) top radiator and (b) bottom view (ground plane).

optimized by the removal of discontinuous points in the radiating structure to reduce the aperture reflections.

The loaded resistance absorbs a part of the residual current. The distributed current mainly concentrates on the tapered feed and resistively loaded slot. Therefore, a slot is introduced into the radiating structure, which produces two current loops. The resistive loading introduced in the middle of the slot enhances current by the creation of additional two small current loops, as shown in Figure 5(b). The resistive loading increases the flow of current in the radiation structure.

3.2. Effect of the Tapered Ground. Many performance parameters are considered in an antenna design to attain a specific objective, such as the size of the radiating structure 
and center frequency. Some adjustments to these parameters were made, and effects on performance are recorded, respectively. Figure 5 shows the effect of ground plane optimization for the bandwidth enhancement of the proposed antenna. The top corners of the ground plane are rounded to reduce aperture reflections and better impedance matching.

The curved ground plane along with the tapered feeding structure is found useful in an enhancement of the lower frequency band. Therefore, in the proposed antenna optimization, the ground plane is used to enhance bandwidth. Figure 6 shows the antenna impedance plot, while Figure 7 shows the time-domain characteristics of the antenna. When an amplitude-modulated Gaussian pulse is applied, the received output signal has a $0.5 \mathrm{~ns}$ time duration with some minor reflections.

\section{Results and Discussion}

The measured reflection coefficient S11 of the fabricated reflector-backed resistively loaded slotted patch antenna (RB-RLSPA) is displayed in Figure 8. The photographs of the antenna measurement setup are shown in Figure 9.

The proposed antenna operates ( $\mathrm{S} 11$ less than $-10 \mathrm{~dB}$ ) in the frequency band from 0.6 to $4.5 \mathrm{GHz}$. Generally speaking, a compact antenna structure can also reduce the antenna's radar cross section to a certain extent, and the reflected radiation energy can illuminate the ground surface. The constructive coupling between the antenna and the reflector leads to a significant increase in the gain of the antenna [26]. The enhancement of gain over the entire frequency band is achieved with a peak gain of $7 \mathrm{dBi}$; the optimal distance between RLSPA and slotted reflector is $5 \mathrm{~cm}$, as displayed in Figure 10.

Despite the reflector, the ultrawideband operation of the proposed antenna is maintained. Figure 11 shows the simulated and measured radiation pattern of the proposed reflector-backed antenna design at $1 \mathrm{GHz}, 2 \mathrm{GHz}, 3 \mathrm{GHz}$, and $4 \mathrm{GHz}$. As it can be observed, the radiation plots are directional at lower frequencies such as 1 and $2 \mathrm{GHz}$. The performance of the proposed antenna is compared with preexisting antennas, and analysis is presented in Table 1.

4.1. Experiment. The performance of the proposed antenna has been evaluated above sandy soil, as shown in Figure 12 [17]. The proposed antenna is placed on the sand surface, whereas a loop antenna as an electromagnetic field sensor was placed under the sandy surface for measurement of reflection coefficient $S_{21}[27,28]$. The result obtained from the electromagnetic field sensor is calculated using Agilent E5071C vector network analyzer and displayed in Figure 13 [29]. Furthermore, it can be noticed that the antenna shows good parasitic coupling performance at a whole frequency band, except for some late time ringing on higher frequencies. However, the variation is too small to be significant for electromagnetic wave behavior, as the coupling levels at all frequency bands stay below $-35 \mathrm{~dB}[30,31]$.

Figure 14 shows the block diagram of the sandbox test setup for the antenna's use as GPR under field conditions

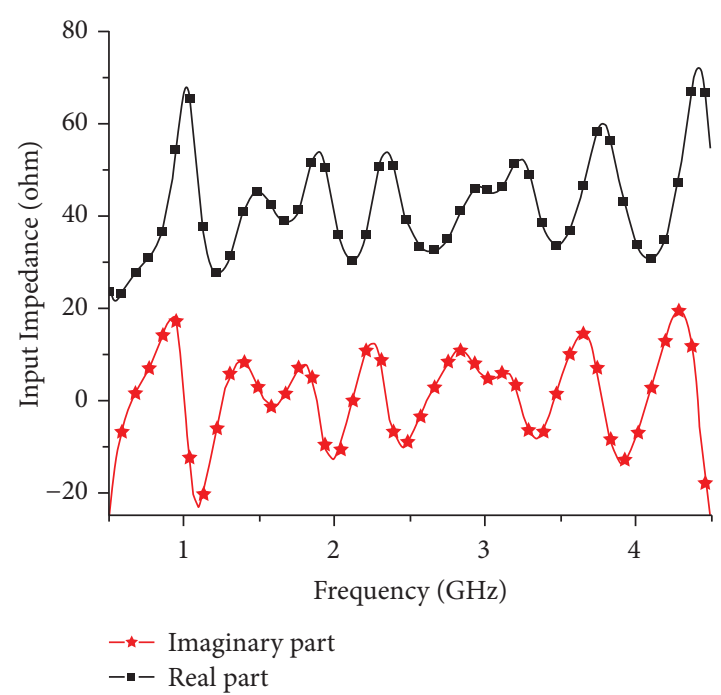

FIGURE 6: Impedance plot of the antenna.

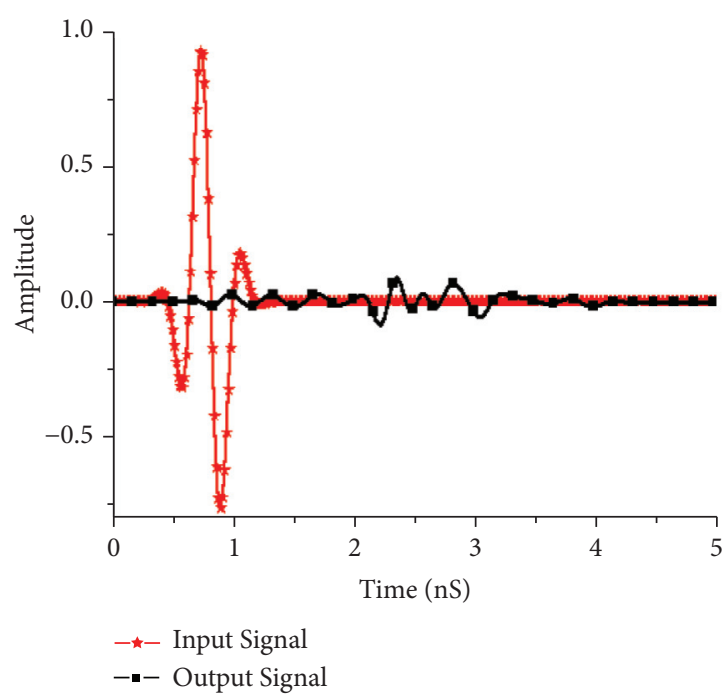

FIgURE 7: Time-domain performance of the proposed antenna.

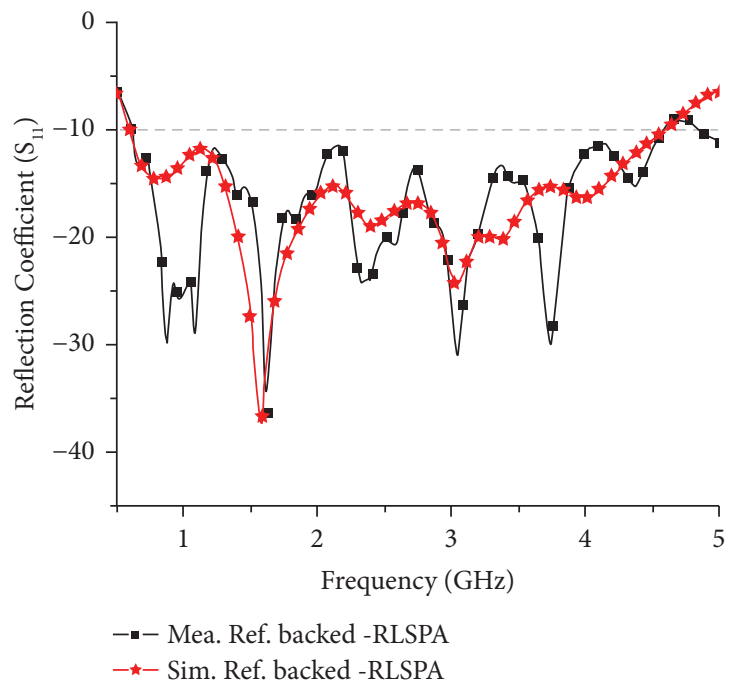

FIgURE 8: Simulated and measured $S 11$ of reflector-backed antenna. 


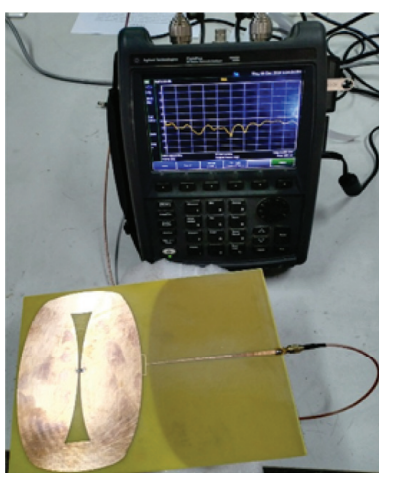

(a)

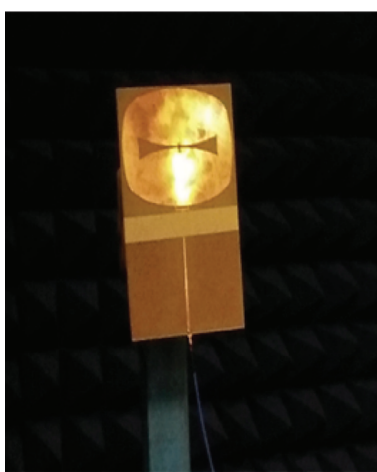

(b)

FIGURE 9: Photographs of the antenna measurement: (a) vector network analyzer (VNA) and (b) anechoic chamber.

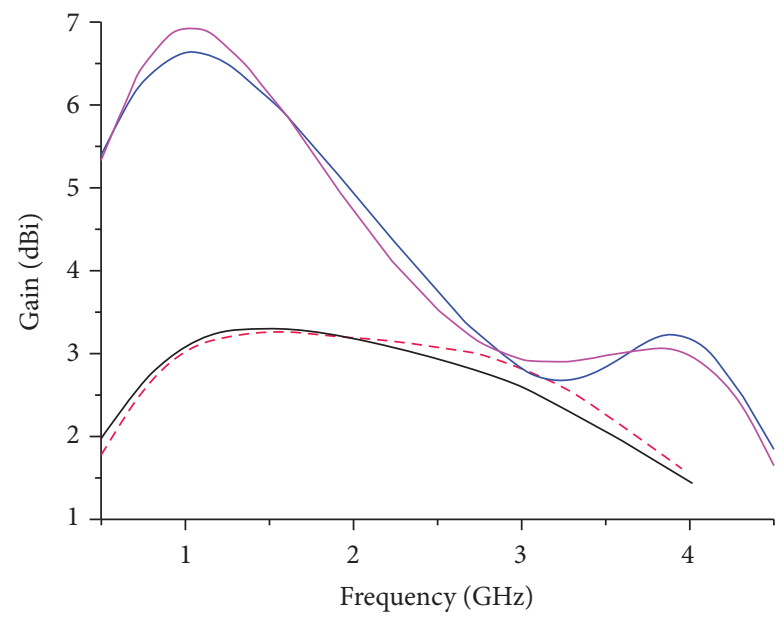

- - Sim. Plannrr Ant. — Sim. Ref. Backed Ant.

FIGURE 10: Simulated and measured gain of the proposed antenna at the different gaps between the reflector and the antenna.

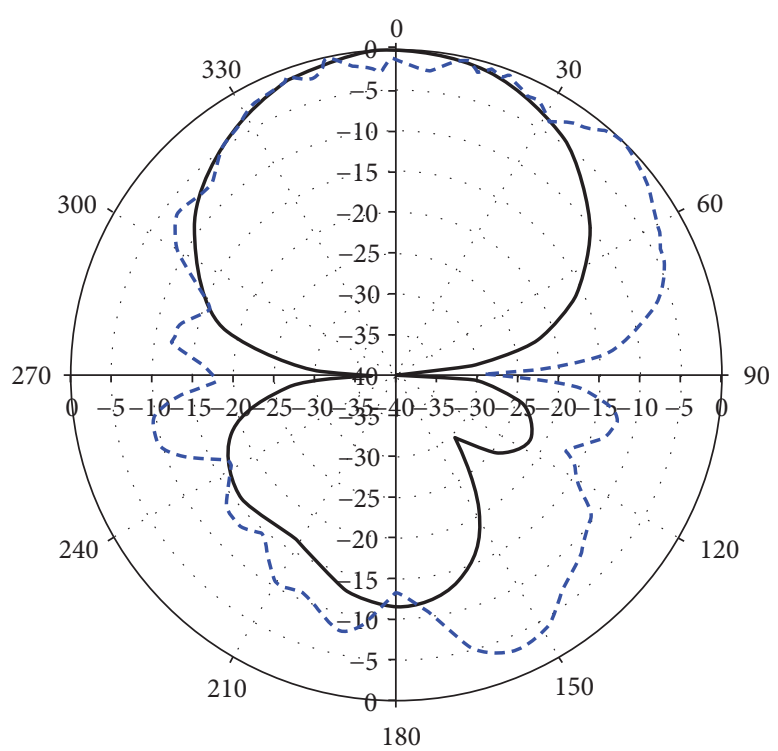

- Simulated - - - Measured

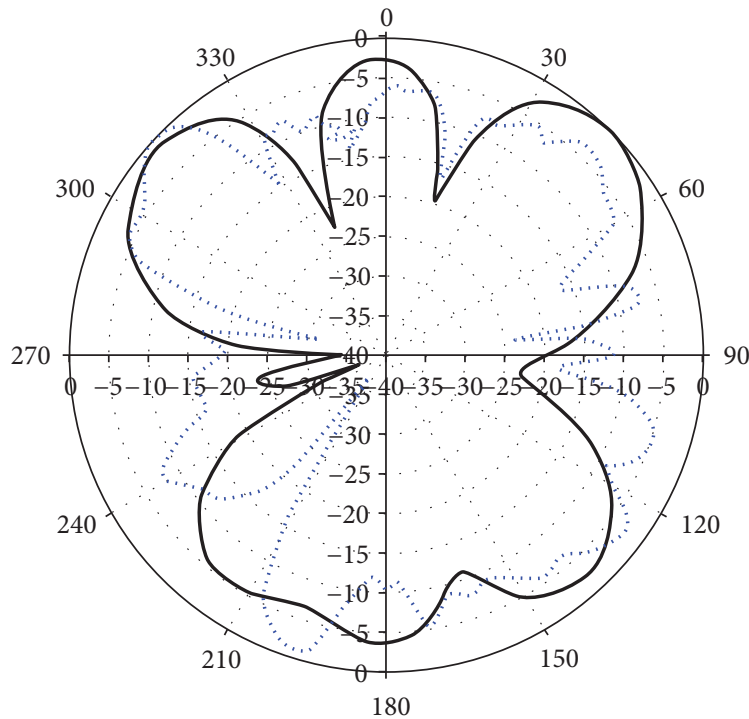

— Simulated Measured

(a) 


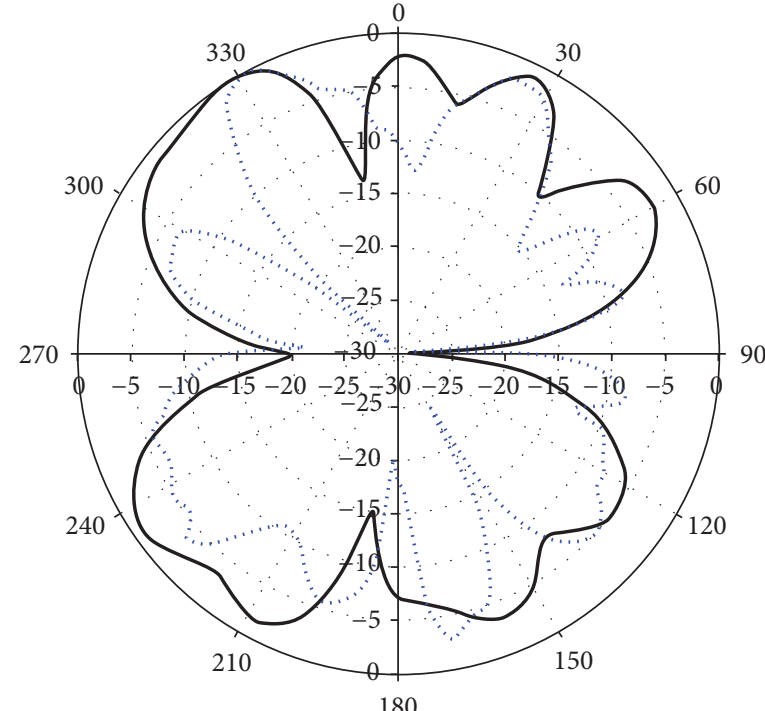

180

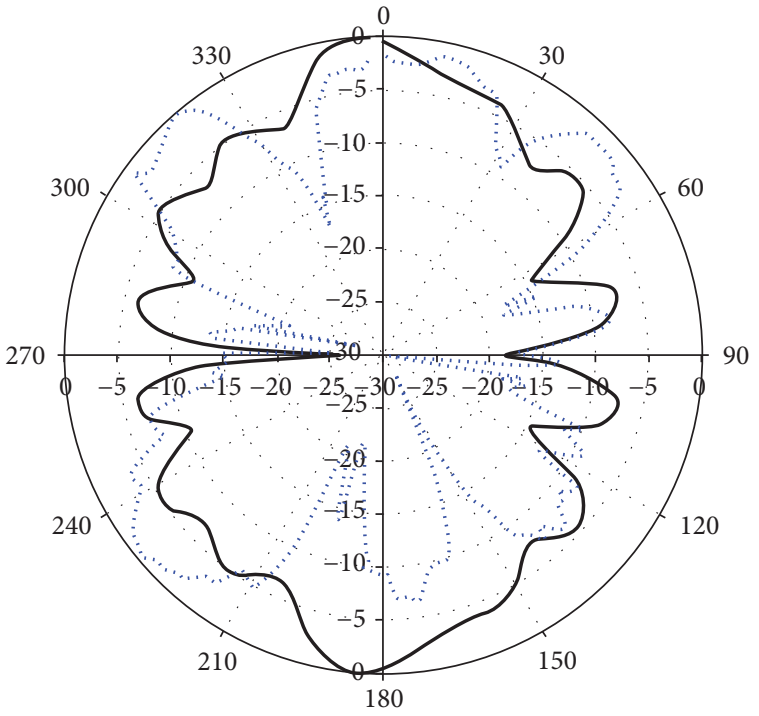

- Simulated

(c)

(d)

Figure 11: Simulated and measured E-plane radiation pattern of reflector-backed RLSPA: (a) $1 \mathrm{GHz}$; (b) $2 \mathrm{GHz}$; (c) $3 \mathrm{GHz}$; (d) 4 GHz.

TABLE 1: Proposed antenna's comparative analysis with already existing antennas.

\begin{tabular}{|c|c|c|c|c|c|c|}
\hline Reference & Shape & Antenna dimensions $\left(\mathrm{cm}^{3}\right)$ & Frequency $(\mathrm{GHz})$ & Peak gain $(\mathrm{dBi})$ & $\begin{array}{l}\text { Complexity/ease of } \\
\text { manufacturing }\end{array}$ & Reflector type \\
\hline [4] & Horn & $25 \times 18 \times 18$ & 0.6 to 6 & 9.91 & Complex/costly & No \\
\hline$[6]$ & Cone & $15.8 \times 15.8 \times 17.4$ & 0.5 to 3 & 4.4 & Complex/costly & No \\
\hline [7] & Sinuous & $10 \times 10 \times 9$ & 2 to 6 & 7 & Complex & No \\
\hline [9] & Slot & $10.7 \times 7 \times 5$ & 1.4 to 3.5 & 6 & Simple & Planner \\
\hline [11] & Bowtie & $27 \times 18 \times 11$ & 0.5 to 3 & 12 & Complex/costly & Cavity \\
\hline [12] & Bow tie & $20 \times 15 \times 4$ & 0.98 to 4.5 & 10.3 & Simple & Cavity \\
\hline$[26]$ & Patch & $20.5 \times 20.5 \times 12$ & 0.433 & 6 & Simple & $\begin{array}{l}\text { Reactive impedance } \\
\text { surface(RIS) }\end{array}$ \\
\hline $\begin{array}{l}\text { Proposed } \\
\text { design }\end{array}$ & $\begin{array}{c}\text { Tapered } \\
\text { feed }\end{array}$ & $18 \times 22 \times 5$ & 0.6 to 4.6 & 7 & Simple & Planner \\
\hline
\end{tabular}

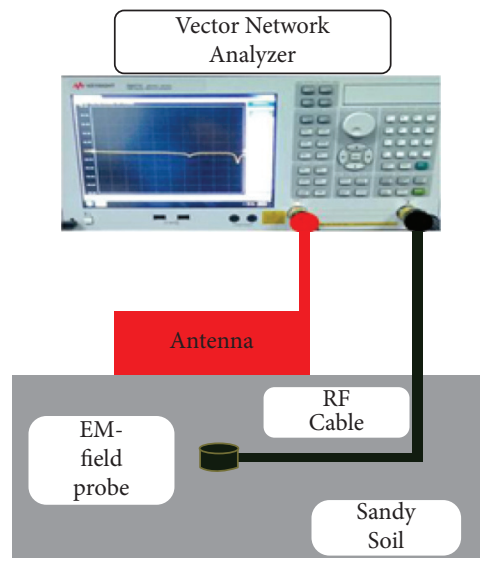

(a)

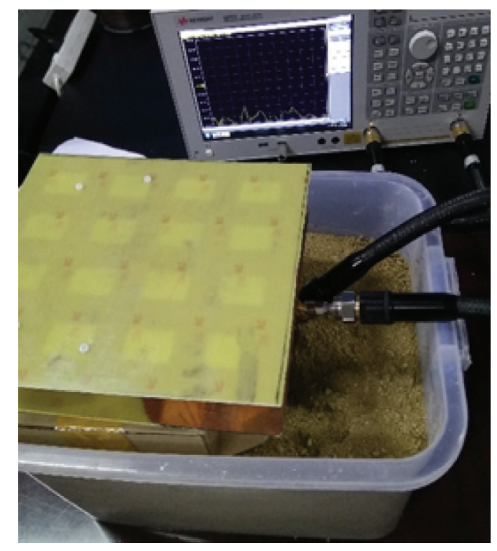

(b)

Figure 12: Sandbox experiment: (a) diagram of the experiment; (b) picture of the experiment. 


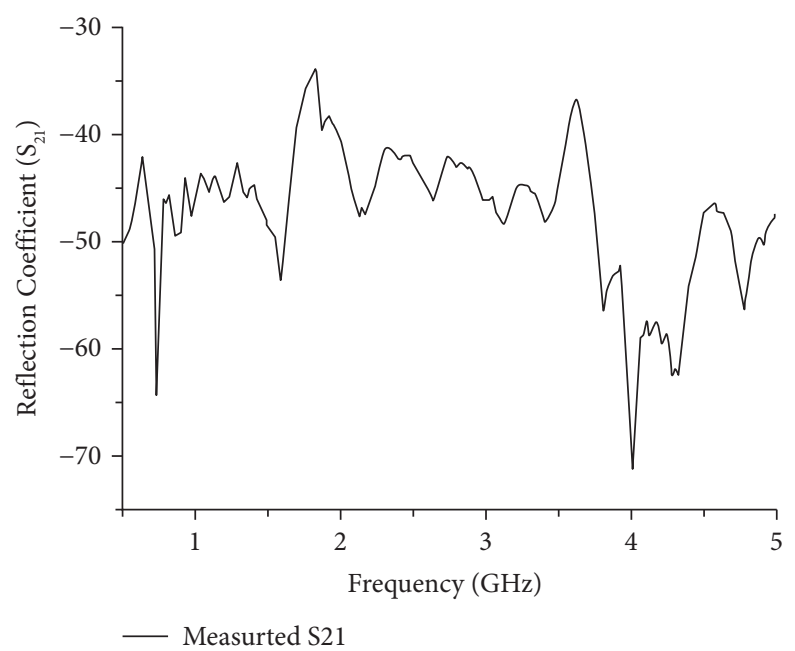

FIGURE 13: Measured $S_{21}$ returns loss of the proposed antenna.

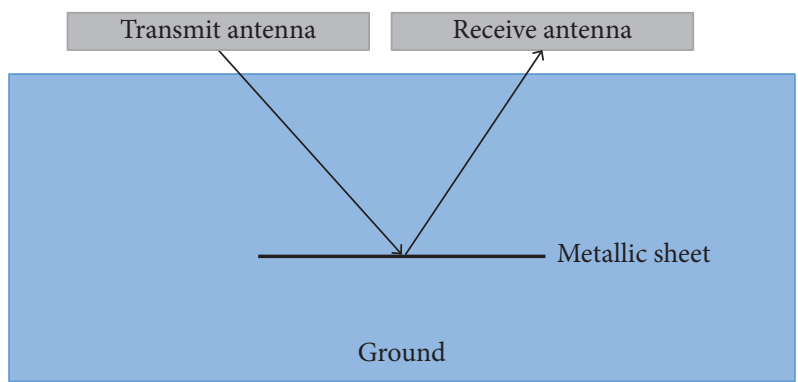

Figure 14: The block diagram of GPR test arrangement in the lab.
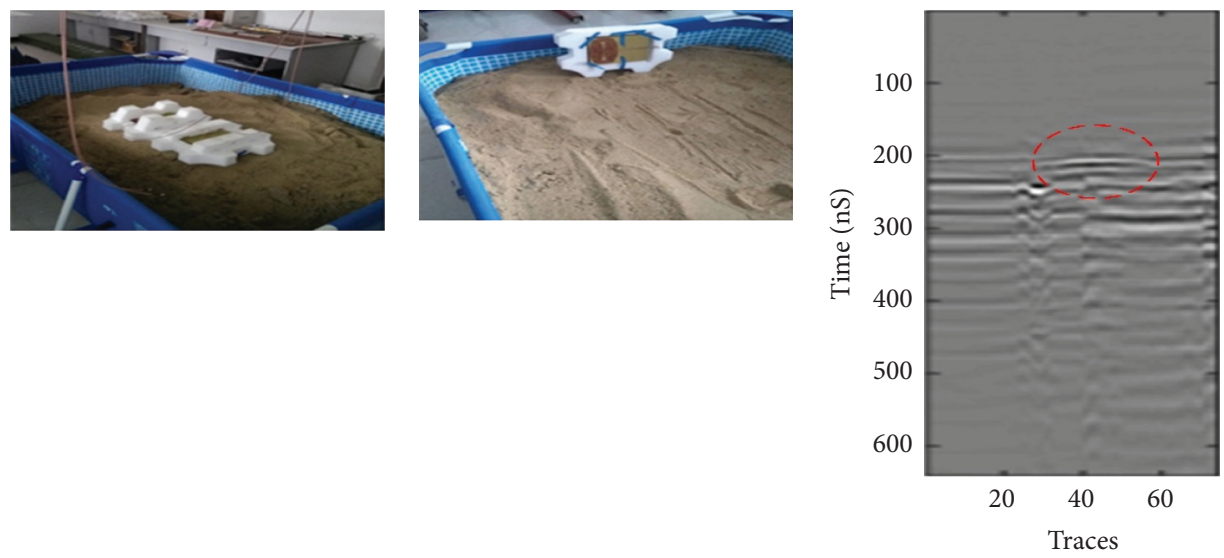

(a)

(b)

(c)

FIGURE 15: The block diagram of GPR test arrangement in the lab.

[10]. While experimentally testing the antenna's ability to be used as GPR, some factors that can affect the detectability of buried objects include uneven surface, airgap between soil and antenna, and the presence of air bubbles under the target surface. Therefore, the height of the antenna above ground is kept very low so that ground acts as a dielectric part of the antenna system. The experimental setup along with the experimental results from the pulse radar system is shown in Figure $15[9,20]$. The hyperbolic reflection curve is observed and highlighted using a red dashed circle, which indicates the detectability of subsurface targets using the proposed antenna in pair configuration [32].

\section{Conclusion}

In this paper, a resistive-loaded wideband slotted patch antenna with optimized performance on low frequencies is proposed for GPR applications. The proposed design 
provides an ultrawide bandwidth ranging from $0.6 \mathrm{GHz}$ to $4.6 \mathrm{GHz}$ with compact dimensions. The fabricated prototype of the antenna along with an integrated reflective surface has overall dimensions of $18 \times 22 \times 5 \mathrm{~cm}^{3}$. The antenna exhibits good radiation characteristics. The presented antenna is suitable for GPR due to its simple structure, eases of fabrication, and low cost. The antenna is experimentally evaluated under soil conditions, as well as its ability to detect buried objects is tested. The experimental results validate the proposed antenna's ability to be used in GPR.

\section{Data Availability}

The data used to support the findings of the study can be obtained from the corresponding author upon request.

\section{Conflicts of Interest}

The authors declare that there are no conflicts of interest regarding the publication of this paper.

\section{Acknowledgments}

This work was supported in part by the National Natural Science Foundation of China (Grant no. 11847307) and China Scholarship Council. The authors would like to thank Mr Jiyu Guo from the School of Resources and Environment, University of Electronic Science and Technology, Chengdu, China, for providing GPR measurement set up.

\section{References}

[1] M. Harry, Ground Penetrating Radar: Theory and Applications, Elsevier Science, England, UK, 2009.

[2] Q. Wang, B. Ai, K. Guan, D. W. Matolak, R. He, and X. Zhou, "Ray-Based statistical propagation modeling for indoor corridor scenarios at $15 \mathrm{GHz}$," International Journal of Antennas and Propagation, vol. 2016, Article ID 2523913, 12 pages, 2016.

[3] W. Wiesbeck, G. Adamiuk, and C. Sturm, "Basic properties and design principles of UWB antennas," Proceedings of the IEEE, vol. 97, no. 2, pp. 372-385, 2009.

[4] A. Ahmed, Y. Zhang, D. Burns, D. Huston, and T. Xia, "Design of UWB antenna for air-coupled impulse groundpenetrating radar," IEEE Geoscience and Remote Sensing Letters, vol. 13, no. 1, pp. 92-96, 2016.

[5] H. Qin and X. Xie, "Design and test of an improved dipole antenna for detecting enclosure structure defects by crosshole GPR," IEEE Journal of Selected Topics in Applied Earth Observations and Remote Sensing, vol. 9, no. 1, pp. 108-114, 2016.

[6] J. Ali, N. Abdullah, and M. Yusof, "Ultra-wideband antenna design for GPR applications: a review," International Journal of Advanced Computer Science and Applications, vol. 8, no. 7, pp. 392-400, 2017.

[7] D. A. Crocker and W. R. Scott, "On the design of sinuous antennas for UWB radar applications," IEEE Antennas and Wireless Propagation Letters, vol. 18, no. 7, pp. 1347-1351, 2019.

[8] J. Shao, G. Fang, Y. Ji, K. Tan, and H. Yin, "A novel compact tapered-slot antenna for GPR applications," IEEE Antennas and Wireless Propagation Letters, vol. 12, no. 1, pp. 972-975, 2013.
[9] M. Li, R. Birken, N. X. Sun, and M. L. Wang, "Compact slot antenna with low dispersion for ground penetrating radar application," IEEE Antennas and Wireless Propagation Letters, vol. 15, pp. 638-641, 2016.

[10] J. Jinjin Shao, G. Guangyou Fang, J. Jingjing Fan, Y. YiCai Ji, and H. Hejun Yin, "TEM horn antenna loaded with absorbing material for GPR applications," IEEE Antennas and Wireless Propagation Letters, vol. 13, pp. 523-527, 2014.

[11] M. Alibakhshikenari, B. S. Virdee, P. Shukla et al., "Impedance bandwidth improvement of a planar antenna based on metamaterial-inspired T-matching network," IEEE Access, vol. 9, pp. 67916-67927, 2021.

[12] M. M. Shirkolaei and M. Jafari, "A new class of wideband microstrip falcate patch antennas with reconfigurable capability at circular- polarization," Microwave and Optical Technology Letters, vol. 62, no. 12, pp. 1-6, 2020.

[13] M. Alibakhshikenari, B. S. Virdee, A. A. Althuwayb et al., "Bandwidth and gain enhancement of composite right left handed metamaterial transmission line planar antenna employing a non foster impedance matching circuit board," Scientific Reports, vol. 11, no. 1, Article ID 7472, 2021.

[14] A. Maleki, H. D. Oskouei, and M. M. Shirkolaei, "Miniaturized microstrip patch antenna with high inter-port isolation for full duplex communication system," International Journal of RF and Microwave Computer-Aided Engineering, vol. 31, 2021.

[15] F. Moayyed, H. R. Dalili Oskouei, and M. Mohammadi Shirkolaei, "High gain and wideband multi-stack multilayer anisotropic dielectric antenna," Progress In Electromagnetics Research Letters, vol. 99, pp. 103-109, 2021.

[16] M. Masoumi, H. R. Dalili Oskouei, M. Mohammadi Shirkolaei, and A. R. Mirtaheri, "Substrate integrated waveguide leaky wave antenna with circular polarization and improvement of the scan angle," Microwave and Optical Technology Letters, pp. 1-5, 2021.

[17] M. Serhir and D. Lesselier, "Wideband reflector-backed folded bowtie antenna for ground penetrating radar," IEEE Transactions on Antennas and Propagation, vol. 66, no. 3, pp. 1056-1063, 2018.

[18] M. Joula, V. Rafiei, and S. Karamzadeh, "High gain UWB bow-tie antenna design for ground penetrating radar application," Microwave and Optical Technology Letters, vol. 60, pp. 2425-2429, 2018.

[19] I. T. McMichael, E. C. Nallon, V. P. Schnee, W. R. Scott, and M. S. Mirotznik, "EBG antenna for GPR colocated with a metal detector for landmine detection," IEEE Geoscience and Remote Sensing Letters, vol. 10, no. 6, pp. 1329-1333, 2013.

[20] K. K. Ajith and A. Bhattacharya, "A novel compact superwideband bowtie antenna for $420 \mathrm{MHz}$ to $5.5 \mathrm{GHz}$ operation," IEEE Transactions on Antennas and Propagation, vol. 66, no. 8, pp. 3830-3836, 2018.

[21] D. J. Sawyer, S. Das, N. Diamanti, A. Peter Annan, and A. K. Iyer, "Choke rings for pattern shaping of a GPR dipole antenna," IEEE Transactions on Antennas and Propagation, vol. 66, no. 12, pp. 6781-6790, 2018.

[22] D. M. Pozar, "Microstrip antennas," Proceedings of the IEEE, vol. 80, no. 1, pp. 79-91, 1992.

[23] M. Ojaroudi, S. Yazdanifard, N. Ojaroudi, and M. NaserMoghaddasi, "Small square monopole antenna with enhanced bandwidth by using inverted T-shaped slot and conductorbacked plane," IEEE Transactions on Antennas and Propagation, vol. 59, no. 2, pp. 670-674, 2011.

[24] A. Raza, W. Lin, Y. Liu, A. B. Sharif, Y. Chen, and C. Ma, “A magnetic-loop based monopole antenna for GPR 
applications," Microwave and Optical Technology Letters, vol. 61, no. 4, pp. 1052-1057, 2019.

[25] M. Wang, Z. Yang, J. Wu et al., "Investigation of SAR reduction using flexible antenna with metamaterial structure in wireless body area network," IEEE Transactions on Antennas and Propagation, vol. 66, no. 6, pp. 3076-3086, 2018.

[26] E. Mohammadi, K. L. Tsakmakidis, F. Sohrabi, A. Tavakoli, and P. Dehkhoda, "Gain enhancement of circular waveguide antennas using near-zero index metamaterials," Microwave and Optical Technology Letters, vol. 61, no. 6, pp. 1617-1621, 2019.

[27] A. Yarovoy, R. de Jongh, and L. Ligthart, "Ultra-wideband sensor for electromagnetic field measurements in time domain," Electronics Letters, vol. 36, no. 20, pp. 1679-1680, 2000.

[28] A. G. Yarovoy, T. G. Savelyev, P. J. Aubry, P. E. Lys, and L. P. Ligthart, "UWB array-based sensor for near-field imaging," IEEE Transactions on Microwave Theory and Techniques, vol. 55, no. 6, pp. 1288-1295, 2007.

[29] H. G. Poley, "GPR antennas design and experimental evaluation," Electrical Engineering Mathematics \& Computer Science, Delft University of Technology, Delft, The Netherlands, 2010.

[30] B. Wu, Y. Ji, and G. Fang, "Analysis of GPR UWB half-ellipse antennas with different heights of backed cavity above ground," IEEE Antennas and Wireless Propagation Letters, vol. 9, pp. 130-133, 2010.

[31] A. Raza, W. Lin, Y. Chen, Z. Yanting, H. T. Chattha, and A. B. Sharif, "Wideband tapered slot antenna for applications in ground penetrating radar," Microwave and Optical Technology Letters, vol. 62, no. 7, pp. 2562-2568, 2020.

[32] J. Guo, J. Tong, Q. Zhao, J. Jiao, J. Huo, and C. Ma, “An ultrawide band Antipodal vivaldi antenna for airborne GPR application," IEEE Geoscience and Remote Sensing Letters, vol. 16, no. 10, pp. 1560-1564, 2019. 